\title{
HIRARKI
}

\section{ANALISIS FAKTOR-FAKTOR YANG MEMPENGARUHI PENDAPATAN INDUSTRI KECIL PENGUSAHA TAHU DI KECAMATAN BONAI DARUSSALAM}

Dewi Supri Anggriani ${ }^{1}$, Makmur $^{2}$, Andi Afrizal ${ }^{3}$

Fakultas Ekonomi, Program Studi Manajemen, Universitas Pasir Pengaraian

\section{Info Artikel}

\section{Sejarah Artikel:} Diterima 23 Agustus 2019

Disetujui 16 September 2019

Dipublikasikan

30 Oktober 2019

\section{Keywords:}

Jam kerja; Lama usaha;

Modal kerja; Pendapatan pengusaha.

\begin{abstract}
Abstrak
Penelitian ini bertujuan untuk mengetahui apa saja faktor-faktor yang mempengaruhi pendapatan pengusaha tahu di Kecamatan Bonai Darussalam, dengan menggunakan pendekatan kuantitatif. Subjek yang menjadi penelitian adalah para pengusaha tahu yang berada di Kecamatan Bonai Darussalam. Metode pengambilan sample adalah random sampling. Sampel dalam penelitian ini berjumlah 39 orang pengusaha.Metode pengumpulan data dalam penelitian ini adalah koesioner. Teknik yang digunakan penelitian ini untuk mendapatkan kesimpulan adalah regresi linier berganda dengan program SPSS, sehingga menghasilkan persamaan: $Y=3,283+0,092 X_{1}+0,280 X_{2}+0,305 X_{3}+$ e. Pengujian hipotesis menggunakan uji $R$, menunjukkan bahwa nilai $R$ Square adalah 0,450 artinya secara bersama-sama variabel bebas memiliki pengaruh sebesar 45,0\% terhadap variabel terikat, dan 9,9\% dipengaruhi oleh variabel bebas lainnya yang tidak termasuk dalam penelitian ini. Dapat disimpukan bahwa faktor-faktor yang mempengaruhi pendapatan pengusaha di Kecamatan Bonai Darussalam adalah variabel independen Modal kerja $\left(X_{1}\right)$, Jam kerja $\left(X_{2}\right)$ dan Lama usaha $\left(X_{3}\right)$.
\end{abstract}

\section{ANALYSIS FACTORS INFLUENCE INCOME ENTREPRENEUR TOFU SMALL INDUSTRY IN BONAI DARUSSALAM DISTRICT}

\begin{abstract}
This study aims to find out factors that influence income of tofu entrepreneurs in Bonai Darussalam District, using quantitative approach. Subject of research was tofu entrepreneurs in Bonai Darussalam District. Sampling method is random sampling. Sample in this study amounted to 39 entrepreneurs. Method of collecting data in this study was questionnaire. Technique used in this study to obtain conclusions is multiple linear regression with the SPSS program, so as to produce the equation: $Y=3.283+0.092 X 1+$ $0.280 X 2+0.305 X 3+e$. Hypothesis testing uses the $R$ test, indicating that the value of $R$ Square is 0.450 means that together the independent variables have influence of $45.0 \%$ on the dependent variable, and $9.9 \%$ is influenced by other independent variables not included in this study. It can concluded factors that influence income of entrepreneurs in Bonai Darussalam district are independent variables of Working Capital (X1), Working hours (X2) and Duration of effort (X3).
\end{abstract}

\footnotetext{
Alamat korespondensi :

Universitas Pasir Pengaraian

Dewisuprianianggraini67@gmail.com
} 


\section{PENDAHULUAN}

Indonesia merupakan salah satu negara yang masuk dalam kategori negara berkembang. Proses transformasi struktural di indonesia berlangsung dengan sangat cepat. Perubahan seperti ini banyak terjadi di semua negara berkembang termasuk indonesia. Daerah-daerah di indonesia mulai mengembangkan sektor industri, sehingga memperkecil kesenjangan dengan sektor pertanian.Arsyad (2010) mengatakan proses industrialisasi dan pembangunan industri sebenarnya merupakan salah satu jalur untuk meningkatkan kesejahteraan masyarakat dalam arti tingkat hidup yang lebih maju maupun taraf hidup yang lebih baik.

Sejalan dengan pelaksanaan otonomi daerah, pemerintah daerah memepunyai kewenangan yang lebih luas dalam menentukan kebijakan dan program pembangunan yang terbaik bagi peningkatan kesejahtraan masyarakat dan kemajuan daerah masing-masing. Pembangunan ekonomi daerah harus disesuaikan dengan keadaan, permasalahan dan peluang yang ada pada daerah yang bersangkutan. Corak yang berbeda antara daerah menyebabkan adanya penanganan yang berbeda dalam menentukan arah perencanaan pembangunannya. Menurut Setyaningrum dkk.(2014), proses pembangunan dan pertumbuhan tidak di sesuaikan dengan potensi yang di miliki daerah.

Tingginya pertumbuhan penduduk dan jumlah penduduk Indonesia akan menghambat pembangunan, apabila tidak diimbagi dengan perluasan kesempatan kerja serta peningkatan mutu tenaga kerja, karna seperti yang diketahui bahwa pemerintah mempunyai keterbatasan dalam hal penyediaan lapangan pekerjaan.

Selain itu, menurut Bakce (2008) keberadaan industri kecil masih terjamin dan potensial untuk berkembang, terutama perusahaan kecil didaerah pedesaan. Perusahaan kecil di Indonesia dilihat dari potensi dan keberadaanya ada harapan untuk berkembang. Industri kecil memiliki peranan yang sangat penting bagi kegiatan Ekonomi Nasional. Misalnya peenciptaan kesempatan kerja, meningkatkan nilai tambah, mempercepat distribusi pendapatan, mendorong pertumbuhan ekonomi dan menjaga stabilitas Nasional.

Nurhayatidkk, (2012) mengemukakan bahwa Industri kecil dan menengah (IKM) adalah kelompok usaha yang mampu menyerap bantak tenaga kerja dan menjadi sumber pendapatan masyarakat.

Saat ini di Kecamatan Bonai Darussalam mulai berkembang industri baik industri bersekala besar maupun industri kecil dan menengah. Perkembangan industri ini yang akan mempengaruhi persaingan industri diantara kalangannya. Karna industri didirikan rata-rata tidak harus membutuhkan lahan yang luas, maka dari itu pengusaha biasanya mendirikan tempat produksi tahunya berdampingan dengan rumah pengusaha tersebut, dan memudahkan pengusaha untuk mengelola usahanya.

Dari data dapat dilihat bahwa usaha tahu di Kecamatan Bonai Darussalam banyak tersebar di setiap desa. Mengalami kemajuan, misalnya terlihat dari lancarnya pemesanan tahu setiap bulannya, pemasaran yang sudah luas dan tahu yang di jual biasanya ada tahu putih dan tahu yang sudah digoreng. Tahu goreng sebenarnya untuk strategi pemasaran karna dapat memudahkan pelanggan yang akan membeli sesuai kebutuhan. Melihat potensinya usaha tahu sangat menjanjikan, karna produk tahu sangat digemari oleh masiyarakat, maupun masiyarakat menengah ke atas maupun menengah kebawah. Hal ini yang sering membuat pengusaha tahu kualahan dalam memenuhi permintaan konsumen karna modal usaha tahu yang masih kurang, sehingga besar kecilnya perkembangan usaha tahu salah satunya dipengaruhi oleh modal usaha, dimana semakin besar modal usaha maka semakin banyak produksi yang mampu dihasilkan guna memenuhi permintaan konsumen. Dengan demikian pendapatan pengusaha tahu juga meningkat. Hal tersebut dapat dibuktikan dengan data yang terlampir dibawah ini. Sebagai contoh data industri tahu di Desa Rawa Makmur Kecamatan Bonai Darussalam.

Jenis kedelai yang di gunakan adalah kedelai inport karna kualitasnya yg lebih bagus dari pada kedelai lokal, nilai jual/harga jual produk tahu yang terjangkau dan penjualannya yang lancar diharapkan dapat meningkatkan pendapatan para kariawan produksi tahu, agar dapat memperbaiki perekonomian. 
Desa Rawa Makmur juga tidak luput dari permasalahan yang di hadapi oleh para karyawannya diantaranya: pertama, masiyarakat yang menjadi karyawan tahu memiliki pendapatan yang berbeda-beda antara karyawan.

Kedua, sulitnya pengembangan usaha produksi tahu karna terbatasnya modal. Ketiga, industri tahu dijalankan secara individu dan persaingan dalam penetapan harga produk tahu antara pengusaha, sehingga menimbulkan persaingan yang tidak sehat dan berpotensi merugikan pihak lain. Keempat, menurunnya minat warga sekitar untuk menjadi karyawan produksi tahu khususnya pada generasi muda yang membuat sulitnya mencari tenaga kerja. Hal ini dapat dilihat dari mayoritas pekerja produksi tahu berusia 30 tahun.

Dengan demikian, untuk mengembangkan usaha produksi tahu ini bisa menambahkan modal usaha yang dimiliki sehingga bisa digunakan sebagai modal awal usaha atau kedepannya bisa menunjang kegiatan usaha agar lebih maju dan memberikan pendapatan yang labih besar. Modal usaha dapat diperoleh sendiri atau mengajukan bantuan kepada pemerintah seperti modal usaha yang biasanya diberikan kepada UKM (Usaha Kecil Menengah) dan sejenisnya.

\section{METODE}

Husaini (dalam Feliatra, 2011) mengatakan populasi yang diartikan sebagai wilayah generalisasi yang terdiri dari objek atau subjek yang mempunyai karakteristik tertentu dan mempunyai kesempatan samauntuk dipilih menjadi anggota sampel. Populasi dalampenelitian ini adalah seluruh pengusaha tahu sebanyak 39 pengusaha. Populasi ini bersifat heterogen, hal inidapat dilihat dari beragam usia, dan jenis kelaminmaupun pendidikan.

Adapun jenis data dalam penelitian ini ada dua data kuantitatif dan data kualitatif. Data Kuantitatif yaitu, Data-data berupa angka-angka yang berhubungan dengan penelitian yang penulis teliti dan kaitkan dengan teori-teori yang ada. Sedangkan Data Kualitatif, yaitu : Data-data yang berupa data selain angka-angka yang diperoleh melalui angket atau kuesioner disusun dalam bentuk tabel-tabel dan presentase, kemudian aspekaspek yang terdapat dalam tabel tersebut di bandingkan atau diintrepretasikan sehingga diproleh pembahasan yang luas dari tabel tersebut. Data yang diperoleh dari perusahaan yang meliputi data mengenai keadaan dan jumlah karyawan, mengenai sejarah berdirinya organisasi perusahaan dan data-data lainnya yang mendukung.

Sumber Data yang digunakan adalah data primer dan data sekunder.Data Primer, yaitu data dan informasi yang di peroleh langsung dari objek penelitian, yaitu dari besarnya pendapatan,dan pembiayaan terhadap masing-masing faktor yang mempengaruhi Modal, tenaga kerja, dan lama usaha. Sementara data sekunder, yaitu data yang berkaitan dengan keberadaan usaha serta kebijakan-kebijakan yang berkaitan dengan UKM yakni Dinas perindag, Bapeda Dinas catatan sipil dan kependudukan serta intansi terkait lainya. Teknik Pengambilan Data dalam penelitian ini adalah Observasi, Kuesioner, Wawancara, Studi Pustaka.

Sugiono (2014) mengatakan instrumen penelitian adalah suatu alat yang digunakan untuk mengukur fenomena alam maupun sosial yang diamati. Dalam penelitian ini instrumen yang digunakan adalah skala pengukuran instrumen artinya dengan menggunakan sekala likert, maka variabel yang digunakan akan diukur dan di jabarkan menjadi indikator variabel kemudian indikator tersebut dijadikan sebagai tolak ukur untuk menyusun item-item intrumen yang berupa pertanyaan atau pernyataan.

\section{HASIL DAN PEMBAHASAN}

Dari ringkasan hasil pengujian validitas valiabel bebas $(\mathrm{X})$ dan variabel terikat $(\mathrm{Y})$ sesuai dengan hasil output SPSS 16 di atas dapat biketahui bahwa hasil yang diperoleh dari variabel $\mathrm{X}$ dan $\mathrm{Y}$ semua valid dikarenakan nilai $r$-hitung $>$ dari $r-$ tabel untuk setiap item yang ada.

Sementara dari hasil uji reliabilitas dapat dijelaskan bahwa semua nilai variabel modal kerja, jam kerja, lama usaha dan pendapatan menunjukan konsistensi yang dapat dipercaya atau reliabel. Hal ini memberikan kesimpulan bahwa semua butir pertanyaan yang menjadi dimensi pengukuran dari variabel yang di amati sudah reliabel. 
Berdasarkan dari koesioner yang telah peneliti sebarkan selama masa penelitian terhadap 39 responden, telah didapatkan jumlah pengusaha yang berada di Kecamatan Bonai Darussalam berdasarkan karakteristik responden, maka dari sampel penelitian sebesar 39 responden dapat dijelaskan karakteristik responden menurut usia 35 tahun hingga 40 tahun berjumlah 15 orang responden atau sebesar $38,5 \%$, yang berusia 40 tahun hingga 45 tahun berjumlah 13 orang responden atau $33,3 \%$, dan yang berusia 45 tahu hingga 50 tahun berjumlah 11 orang responden atau sebesar 28,2\%. Adapun jumlah responden berdasarkan jenis kelamin laki-laki 20 orang responden atau sebesar $51 \%$ dan jenis kelamin perempuan 19 orang respondenatau sebesar 48,1\%. Dalam penelitian ini karakteristik responden berdasarkan jenis kelamin lebih dominan kepada jenis kelamin laki-laki.

Variabel yang menggunakan dalam penelitian ini adalah variabel Modal kerja (X1), Jam kerja (X2) dan Lama usaha (X3)ketiga variabel ini merupakan variabel independent dan variabel pendapatan pengusaha (Y) merupakan variabel dependent.

Berdasarkan hasil uji $\mathrm{R}^{2}$, dimana nilai $\mathrm{R}$ Square adalah 0,450 artinya secara bersamasama variabel bebas (Modal kerja (X1), Jam kerja (X2), Lama usaha (X3)) memiliki pengaruh sebesar $0,450 \%$ terhadap variabel terikat (Pendapatan pengusaha (Y)), dan 9,9\% dipengaruhi variabel bebas lainnya diluar variabel penelitian ini.

Berdasarkan Uji F menunjukkan Uji koefisien secara simultan/uji $\mathrm{F}$ signifikan $(\mathrm{p}=$ 0,000). Karena probabilitasnya lebih kecil dari 0,05 maka model regresi dapat digunakan untuk memprediksi pendapatan pengusaha (Y), dari hasil yang diperoleh dapat diartikan bahwa variabel independent mempengaruhi variabel dependent.

Sedangkan Uji t koefisien regresi yang signifikan (sig. < 0,05) adalah Modal kerja (X1) dan Jam kerja (X2), sedangkan yang signifikan adalah Lama usaha(X3) hasil uji koefisien secara simultan / Uji F signifikan ( $\mathrm{p}$ $=0,000)$. Karena probabilitasnya lebih kecil dari 0,05 maka model regresi dapat digunakan untuk memprediksi pendapatan pengusaha (Y). Maka dapat diartikan bahwa variabel independen Modal kerja dan jam kerja mepengaruhi variabel dependen pendapatan pengusaha (Y) di Kecamatan Bonai Darussalam.
Hasil analisis regresi linier berganda menunjukan bahwa variabel modal kerja (X1) bernilai 0,092 yang mengakibatkan kenaikan pendapatan pengusaha sebesar 9,2\%, variabel jam kerja (X2) bernilai 0,280 yang mengakibatkan kenaikan pendapatan pengusaha sebesar 28,0\% dan variabel Lama usaha (X3) bernilai 0,305 yang mengakibatkan kenaikan pendapatan pengusaha sebesar $30,5 \%$.

Dan penelitian sebelumnya yang diteliti sebelumnya yang dilakukan oleh Cahayadi (2016) dengan judul penelitian "Faktor Internal Dan Esternal Yang Berpengaruh Pada Pendapatan Pasar Seni Sukawati Setelah Berkembangnnya Pasar Oleh-Oleh Moderen Di Kabupaten Gianyar" hasil yang diperoleh bahwa variabel yang berpengaruh positif terhadap pendapatan pedagang pasar seni sukawati adalah lokasi usaha dan modal usaha, sedangkan lama usaha dan jam kerja tidak mempengaruhi.

Selanjutnya penelitian yang dilakukan oleh Romadhoni (2016) dalam penelitiannya dengan judul penelitian "Analisis Pendapatan Pedagang Sektor Informal Di Kawasan Religi (Studi Pada Pedagang Kaki Lima Di Kawasan Makam Gus Dur Dusun Tebuireng, Kecamatan Diweek, Kabupaten Jombang, Jawa Timur)" menyatakan bahwa secara positif variabel modal, jam kerja kerja, lokasi lama usaha, dan usaha mempengaruhi pendapatan pedagang.

Maka dari penelitian sebelumnya dapat diambil kesimpulan bahwa penelitian ini sesuai dengan penelitian Romadhoni (2016) pada variabel lokasi usaha, modal usaha, dan jam kerja pedagang. Dan pada variabel lama usaha sesuai dengan penelitian yang dilakukan oleh Cahyadi (2016).

Dapat disimpulkan bahwa variabel yang mempengaruhi Pendapatan Pengusaha Pada Industri Kecil Tahu Di Kecamatan Bonai Darussalam adalah variabel Modal kerja (X1) dan Jam kerja (X2). Sedangkan variabel Lama usaha (X3) berpengaruh negatif. 
Tabel 1. Hasil Regresi Linier Berganda

\section{Coefficients $^{\mathrm{a}}$}

\begin{tabular}{|c|c|c|c|c|c|c|}
\hline \multirow{2}{*}{\multicolumn{2}{|c|}{ Model }} & \multicolumn{2}{|c|}{ Unstandardized Coefficients } & \multirow{2}{*}{$\begin{array}{c}\text { Standardized } \\
\text { Coefficients } \\
\text { Beta }\end{array}$} & \multirow[b]{2}{*}{$\mathrm{t}$} & \multirow[b]{2}{*}{ Sig. } \\
\hline & & B & Std. Error & & & \\
\hline \multirow[t]{4}{*}{1} & (Constant) & 3.283 & 2.488 & & 1.319 & 196 \\
\hline & $\mathrm{x} 1$ & .092 & .129 & .103 & .713 & .481 \\
\hline & $\mathrm{x} 2$ & .280 & 148 & .279 & 1.887 & .067 \\
\hline & $x 3$ & .305 & .094 & .450 & 3.228 & .003 \\
\hline
\end{tabular}

a. Dependent Variable: $y$

\section{Coefficients $^{\mathrm{a}}$}

\begin{tabular}{|c|c|c|c|c|c|c|c|c|}
\hline \multirow{6}{*}{1} & \multirow{3}{*}{$\begin{array}{l}\text { Model } \\
\text { (Constant) }\end{array}$} & Unstandar & Coefficients & \multirow{2}{*}{$\begin{array}{c}\text { Standardized } \\
\text { Coefficients }\end{array}$} & \multirow[b]{2}{*}{$\mathrm{T}$} & \multirow[b]{2}{*}{ Sig. } & \multicolumn{2}{|c|}{ Collinearity Statistics } \\
\hline & & $\mathrm{B}$ & Std. Error & & & & Tolerance & VIF \\
\hline & & 3.283 & 2.488 & & 1.319 & .196 & & \\
\hline & $x 1$ & .092 & .129 & .103 & .713 & .481 & .757 & 1.321 \\
\hline & $x 2$ & .280 & .148 & .279 & 1.887 & .067 & .716 & 1.396 \\
\hline & $x 3$ & .305 & .094 & .450 & 3.228 & .003 & .809 & 1.236 \\
\hline
\end{tabular}

a. Dependent Variable: $y$

Sumber : Data primer diolah 2019

\section{KESIMPULAN}

Dari analisis data dan pembahasan yang telah diuraikan pada bab sebelumnya, maka dapat diambil kesimpulan sebagai berikut, Modal kerja yang dimiliki pengusaha industri kecil tahu di Kecamatan Bonai Darussalam sudah cukup baik. Ini dapat disimpulkan bahwa pengusaha sudah memiliki modal kerja yang cukup baik dalam hal membangun usahanya agar lebih maju. Jam kerja di industri kecil tahu yang ada di Kecamatan Bonai Darussalam sudah cukup baik. Hal ini berarti pengusaha sudah memiliki standar usaha dan layak untuk membangun usahanya, serta memperhatikan karyawan dengan baik.

Lama usaha yang dimiliki oleh usaha industri kecil tahu di Kecamatan Bonai Darussalam tidak menjamin keberhasilan usaha tersebut, dalam artian tidak menjamin meningkatnya pendapatan pengusaha tanpa memperhatikan strategi usaha yang baik.

Modal kerja, Jam kerja dan lama usaha memperoleh pengaruh yang positif dan signifikan terhadap pendapatan pengusaha industri kecil tahu di Kecamatan Bonai Darussalam dapat diterima. Hal ini ditunjukkan oleh hasil penelitianyang menunjukkan bahwa besarnya pengaruh Modal kerja, Jam kerja dan Lama usaha secara bersama-sama berpengaruh positif terhadap pendapatan pengusaha. Sedangkan sisanya dipengaruhi oleh variabel lain yang tidak diteliti.

\section{SARAN}

Berdasarkan kesimpulan yang telah dijelaskan, maka dapat diberikan saran dalam penelitian ini yaitu, Bagi pemerintah sebaiknya mempertimbangkan hasil penelitian ini sebagai bahan pertimbangan dalam membuat beberapa kebijakan untuk mendata ulang seluruh usaha industri kecil khususnya tahu yang ada di Kecamatan Bonai Darussalam, untuk memudahkan pemerintah menyalurkan program pemerintah seperti pinjaman usaha. Agar dapat memajukan usaha-usaha yang ada dan dapat memajukan perekonomian masyarakat. 
Bagi pengusaha yang berada di Kecamatan Bonai Darussalam sebaiknya lebih memperhatikan jumlah jam kerja yang digunakan, karena jam kerja yang terlalu tinggi dan dilakukan secara rutin dapat menimbulkan dampak yang tidak baik bagi kesehatan maupun dampak yang lainnya. Dan hendaknya juga bagi pengusaha agar lebih peduli lagi dalam menjaga kebersihan, baik kebersihan tempat industri maupun lingkungan sekitar.

Bagi pihak-pihak yang akan melakukan penelitian lebih lanjut terhadap pembahasan ini sebaiknya perlu mengkaji ulang baik mengenai variabel yang dipakai maupun pengkajian lebih dalam terkait variabel yang digunakan dalam penelitian ini.

\section{DAFTAR PUSTAKA}

Ahmad Su'ud, 2007, Pengembangan ekonomi mikro, Nasional Conference, Jakarta

Anjung. 2013. Akuntansi Pemerintah Daerah Berbasis Akrual. Cetakan Kedua. Alfabeta. Bandung.

Arikunto, S. 2010. Prosedur Penelitian Suatu Pendekatan Praktik. Jakarta: Rineka Cipta.

Arikunto. 2006. Prosedur Penelitian Suatu Pendekatan Praktek. Jakarta : PT. Rineka Cipta

Asruni, 2017. Faktor - faktor yang mempengaruhi pendapatan usaha kecil dan menengah $(U K M)$ : Di kabupaten Hulu sungai Selatan Provinsi Kalimantan selatan.

Asmie. 2008. Analisis Faktor-Faktor Yang Mempengaruhi Tingkat Pendapatan Pedagang Pasar Tradisional di Kota Yogyakarta. Yogyakarta : Universitas Gajah Mada.

Aulia Rahma, 2011, Analisis Pengaruh manajemen Modal Kerja Terhadap Profitabilitas Perusahaan (Studi Pada Perusahaan Manufaktur PMA dan PMDN Yang Terdaftar di BEI periode 2004-2008), Fakultas Ekonomi Universitas Diponegoro Semarang.

Badan Statistik, 2008. Pendataan Program Perlindungan Sosial Tahun 2008. Jakarta Pusat: Badan Pusat Statistik.
Budi Wahyono, 2017. Analisis faktor-faktor yang mempengaruhi pendapatan pedagang di pasar bantul kabupaten bantul.

Candora, 2013.Analisis Faktor-Faktor Yang Mempengaruhi Pendapatan Pengrajin Batik Kayu (Kasus Pada Sentra Industri Kerajinan Batik Kayu Di Dusun Krebet, Desa Sendangsari, Kecamatan Pajangan, Kabupaten Bantul, Daerah Istimewa Yogyakarta Tahun 2013).

Depdiknas. 2001. Kamus Besar Bahasa Indonesia. Jakarta: Balai pustaka

Dumairy, 1996, Perekonomian Indonesia, Jakarta : BPFE.

Dwi, 2017.Analisis faktor-faktor yang mempengaruhi pendapatan pengrajin bambu (Studi pada sentra industry kerajinan bambu di desa jambu kulon kecamatan ceper kabupaten klaten).

Eko purwaningsih. 2007.Cara pembuatan Tahu dan manfaat kedelai. kawasan industry $j l$. $P$ selayar kv.A5, bekasi

Gajimu.com -Pertanyaan mengenai jam kerja di Indonesia

Ghozali. 2011. Aplikasi Analisis Multivariate Dengan Program IBM SPSS 19 (edisi kelima.) Semarang: Universitas Diponegoro

Gestry Romaito Butarbutar. 2017 Analisis Faktor-Faktor Yang Mempengaruhi Pendapatan Usaha Industri Makanan Khas Di Kota Tebing Tinggi

Ghozali. 2012. Aplikasi Analisis Multivariate dengan Program IBM SPSS 20. Semarang: Badan Penerbit Universitas Diponegoro

Halim. 2011. Analisis Investasi. Edisi kedua. Jakarta: Salemba Empat.

Husaini. 2011. Manajemen. Teori, Praktik, dan Riset Pendidikan. Bumi Aksara. Jakarta.

https://www.ruangguru.co.id/pengertian-sampelmenurut-para-ahli-beserta-definisinyalengkap/ 12/02/2019

Indri Handayani iMe Site. 2019. Tujuan dan manfaat penelitian. 
Indriyo. 1992. Manajemen Keuangan. Edisi Kedua Yogyakarta : BPFE Yogyakarta.s

Indra Fauzi, 2018.analisis faktor faktor yang mempengaruhi tingkat pendapatan usaha mikro nasabah pembiayaan bmt (studi pada bmt at taqwa kemangisan periode 2017)

Ismi Herdyanti, 2013.Pentingnya modal kerja dalam perusahaan.

Kamaruddin. 1997. Dasar-Dasar Manajemen Modal kerja. Jakarta : PT. Rineka Cipta.

Kartadinata.(1999). Pembelanjaan. Penerbit Rineka Cipta, Jakarta

Kasmir.(2011). "Analisis Laporan Keuangan", Raja Grafindo Persada: Jakarta.

Lia 2007.Analisis pengukuran faktor-faktor yang mempengaruhi tingkat produktivitas tenaga kerja wanita pada sektor industri kecil rumah tangga

di wilayah serangdan cilegon dalam jurnal ekonomi.

Hariwijaya, M. dan Bisri M. Djaelani, 2008, Teknik Menulis Skripsi dan Thesis, Yogyakarta: Hanggar Kreator

Munandar, M.2006. Pokok-pokok Intermadiate Accounting. Gajah mana university press; Yogyakarta.

Martono Dan Harjito.2003. Manajemen Keuangan. Yogyakarta : Ekonisia.

Munawir. 1995. Analisis Laporan Keuangan, Edisi Keempat Cetakan Kelima, Liberti Jogya, Yogyakarta.

Nency Yella Tragindi, Nanik Istiyani dan Teguh Hadi P. (2015) Faktpr-Faktor yang Mempengaruhi Pendapatan Pengusaha Industri Kecil Mebel Di Kecamatan Bondowoso Kabupaten Bondowoso.

Nislah khoirunnisah. 2017. Analisis faktor-faktor yang mempengaruhi pendapatan pedagang di kawasan wisata religi masjid agung islamic centre rokan hulu.

Nur Hidayati. 2007. Analisis pendapatan hom industry (pengolahan tahu) didesa beji batu malang
Nur Istiqomah. 2004. Lamanya Seseorang Maтри Bekerja Secara Baik, Hubungan Antara Waktu Kerja Dengan Waktu Istirahat, Jam Kerja Sehari Meliputi Pagi, Siang, Sore Dan Malam.

Putri Jamaika, Iwayan Subagirta, Sebastian Viphimdrartin (2014) Analisis Faktor Faktor Yang Mempengaruhi Pendapatan Mebel DiKecamatan Leces Kabupaten Probolinggo.

Putri Jamaika, I Wayan Subagirta, Sebastiana Viphindrartin. 2014. Analisis Faktor Yang Mempengaruhi Pendapatan Pengusaha Mebel DiKecamatan Leces Kabupaten Probolinggo.

Rosetyadi Artistyan. 2012. Pengaruh Modal Awal, Lama Usaha, Jam Kerja Terhadap Pendapatan Pedagang Kiyos Di Pasar Bintaro Demak.Skripsi. Fakultas Ekonomika Dan Bisnis. Universitas Di Ponegoro. Semarang.

Romadhoni Binti, ragil. 2016. Analisis pendapatan pedagang sektor informal di kawasan wisata religi (studi pada pedagang kaki lima di kawasan makam gusdur dusun tebu ireng kecamatan diwek. kabupaten jombang jawa timur).

Sukirno. 2000. Makroekonomi Modern. Jakarta: PT Drafindo Persada.

Sugiyono, 2008.Metode Penelitian Kunatitatif Kualitatif dan R\&D. Bandung Alfabeta

Sugiyono. 2012. Metode Penelitian Kuantitatif Kualitatif dan R\&D. Bandung: Alfabeta.

Sugiyono. 2013. Metode Penelitian Pendidikan Pendekatan Kuantitatif, Kualitatif, dan $R \& D$. Bandung: Alfabeta.

Sugiyono. 2014. Metode Penelitian Pendidikan Pendekatan Kuantitatif, Kualitatif Dan $R \& D$. Bandung: Alfabeta.

Todaro, M. P. 2003. Pembangunan Ekonomi di Dunia Ketiga.Jilid 1.Edisi kedelapan. Jakarta: Erlangga

Wasis Edhi Wibowo. (2012) Analisis FaktorFaktor yang Mempengaruhi Tingkat Pendapatan pada Usaha Kecil Menengah (Studi diKota Madiun). 
Widodo.(2005) Perencanaan Sistem Dan Aplikasi Mikrokontroler. Jakarta: Pt. Elex Media Komputindo.

Winardi, 2012. "Pengaruh Budaya Organisasi dan Motivasi Terhadap Kinerja Karyawan dengan Komitmen Organisasional sebagai Variabel Intervening (Studi pada Karyawan Dinas Pengairan Provinsi Aceh)”. Jurnal Ilmu Manajemen, Vol. I, Tahun I, No. 1, Mei 2012 (sesuaikan)

Yunarni, Sriama. 2016. Faktor-Faktor Yang Mempengaruhi Produksi Industri Tenun Di Kecamatan Sipirok Kabupaten Tapanuli Selaran Sumatera Utara. Sekripsi. Fakultas Ekonomi Universitas Riau. Pekanbaru. 